Pontifícia Universidade $_{\text {Do Rio de Janeiro }}$

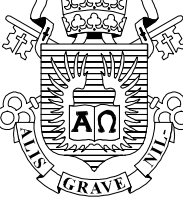

Madalena Simões de Almeida Vaz Pinto

Modernismo em língua desdobrada

Portugal e Brasil

Tese de Doutorado

Tese apresentada ao Programa de Pós-Graduação em Letras da PUC-Rio como requisito parcial para obtenção do título Doutor em Letras

Orientadora: Cleonice Berardinelli 


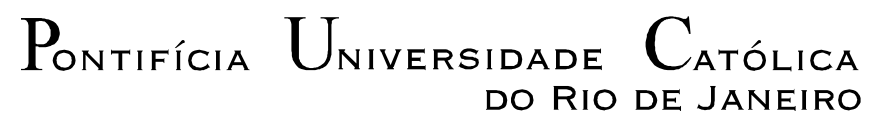

DO RIO DE JANEIRO

Madalena Simões de Almeida Vaz Pinto

\title{
MODERNISMO EM LÍNGUA DESDOBRADA Portugal e Brasil
}

\begin{abstract}
Tese apresentada como requisito parcial para obtenção do grau de Doutor pelo programa de Pós-Graduação em Letras do Departamento de Letras do Centro de Teologia e Ciências Humanas da PUC-Rio. Aprovada pela Comissão Examinadora abaixo assinada.
\end{abstract}

Profa. Cleonice Serôa da Motta Berardinelli Orientadora

Departamento de Letras - PUC-Rio

Prof. Eduardo Jardim de Moraes Departamento de Filosofia - PUC-Rio

Prof. Júlio Cesar Valladão Diniz Departamento de Letras - PUC-Rio

Profa. Maria Eugênia da Gama Alves Boaventura Dias Departamento de Teoria da Literatura - UNICAMP

Profa. Ida Maria Santos Ferreira Alves

Departamento de Letras Clássicas e Vernáculas - UFF

Prof. Paulo Fernando Carneiro de Andrade Coordenador Setorial do Centro de Teologia e Ciências Humanas - PUC-Rio

Rio de Janeiro, de de 
Todos os direitos reservados. É proibida a reprodução total ou parcial do trabalho sem autorização da universidade, da autora e do orientador.

\section{Madalena Simões de Almeida Vaz Pinto}

Licenciou-se em Inglês-Português na PUC-Rio em 1998. Desde então é pesquisadora e professora de literatura portuguesa. Em 1998 obteve o título de mestre em Literatura Portuguesa na mesma universidade com a dissertação "Eça-Pessoa: Atitudes terapêuticas em relação à mentalidade portuguesa". Doutorou-se em 2007 na PUC-Rio com a tese "Modernismo em língua desdobrada: Portugal e Brasil. É diretora do Centro de Estudos do Real Gabinete Português de Leitura e coordenadora do núcleo Cultura e Sociedade de Pólo de Pesquisas do Real Gabinete Português de Leitura.

Ficha Catalográfica

Pinto, Madalena Vaz

Modernismo em língua desdobrada: Portugal e Brasil: / Madalena Vaz Pinto ; orientadora: Cleonice Berardinelli. - 2007. 137 f. ; $30 \mathrm{~cm}$

Tese (Doutorado em Letras)-Pontifícia Universidade Católica do Rio de Janeiro, Rio de Janeiro, 2007.

Inclui bibliografia

1. Letras - Teses. 2. Modernismoportuguês. 3. Modernismo-brasileiro. 4. Literatura comparada. I. Berardinelli, Cleonice. II. Pontifícia Universidade Católica do Rio de Janeiro. Departamento de Letras. III. Título. 


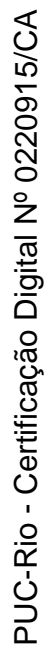

Ao Martim e à Helena, com amor. 


\section{AGRADECIMENTOS}

À Fundação Calouste Gulbenkian pela concessão da bolsa que permitiu esta pesquisa.

À professora Cleonice Berardinelli por ter aceitado ser minha orientadora apesar das condições adversas.

À professora Ida Alves a interlocução amiga e atenta.

Ao Luiz Camillo a amorosa interlocução.

Aos meus filhos, Ricardo e Catarina, por aturarem uma mãe às vezes "chata".

Aos meus irmãos, pelo acompanhamento carinhoso "à distância". 


\section{RESUMO}

Vaz Pinto, Madalena Simões de Almeida; Berardinelli, Cleonice. Modernismo em língua desdobrada: Portugal e Brasil. Rio de Janeiro, 2007, 137 p. Tese de doutorado - Departamento de Letras, Pontifícia Universidade Católica.

Os Modernismos português e brasileiro iniciam-se com sete anos de diferença (1915 - 1922), o português com a publicação da revista Orpheu, o brasileiro com a Semana de Arte Moderna. Como países à margem dos centros hegemônicos, Portugal e Brasil convivem com um déficit de autonomia cultural. O modernismo representa, nos dois casos, ainda que partindo de pressupostos distintos, uma forma de superação dessa desvalia. Se era essencial "ser absolutamente moderno", como dizia Rimbaud, tal postura implicava uma ruptura com a tradição, e, como conseqüência, uma releitura da própria história. É nesse ponto que os caminhos começam a bifurcar-se. No caso do Brasil, esta releitura estará marcada pela necessidade de reformulação-libertação do seu papel de ex-colônia; no caso de Portugal, a questão do império, quando abordada, será tratada por sua carga simbólica, desvinculada da existência concreta das colônias, uma vez que a prioridade era europeizar o país. Para discutir estas diferenças vamos concentrar-nos nas obras de Almada Negreiros e Oswald de Andrade e ver como nelas se dá a relação entre elaboração de uma cultura nacional e invenção de uma nova linguagem.

\section{Palavras chave}

Modernismo-português, modernismo-brasileiro, literatura comparada. 


\section{ABSTRACT}

Vaz Pinto, Madalena Simões de Almeida; Berardinelli, Cleonice. Modernismo em língua desdobrada: Portugal e Brasil. Rio de Janeiro, 2007, 137 p. Thesis Departamento de Letras, Pontifícia Universidade Católica.

Portuguese and Brazilian modernist movements started between 1915 and 1922, with the Orpheu Magazine and the "Week of Modern Art", respectively. As both nations were at the margins of the hegemonic centers, they parthake a deficit in cultural autonomy. Modernism represented for them, although for different reasons, the possibility of overcoming this deficit. If it was essential to be absolutely modern, as Rimbaud said, a rupture with tradition was necessary, opening the way for a re-reading of their own history. At that point their routes started to diverge. For Brazil, this rereading signified a rupture with its colonial past. For Portugal, the priority was to become european and the imperial issue, when discussed, incorporated a symbolic tone, divorced from the concrete existence of its colonies. To discuss those differences, we will focus on the writings of Almada Negreiros and Oswald de Andrade. Through their works, we will relate national identity with the invention of a new language.

\section{Key words:}

Portuguese-modernism, brazilian-modernism, comparative-literature. 


\section{SUMÁRIO}

Introdução 9

1. Modernidade

1.1 Modernidade: conceituação 13

1.2 Modernidade, modernismos 17

1.3 Modernidade e linguagem 21

2. Paris não é aqui

2.1 Vanguardas em Portugal e no Brasil 24

2.2 Conceituação vanguardas periféricas $\quad 28$

2.3Caráter literário das vanguardas periféricas 34

2.4Um pouco de Europa na alma 37

2.5Antecedentes Geração de Orpheu 39

2.6Antecedentes Semana de Arte Moderna 46

3. Futurismo como desejo de futuro

3.1 Textos de Intervenção: Almada Negreiros $\quad 49$

3.2 Textos de intervenção: Oswald de Andrade $\quad 60$

3.3 Conclusão 68

4. Ficcionalizar para existir

4.1 Invenção de uma linguagem $\quad 71$

4.2 Histoire du Portugal par coeur $\quad 77$

4.3 Poesia Pau Brasil $\quad 94$

4.4 Conclusão 112

$\begin{array}{ll}\text { Bibliografia } & 117\end{array}$

Anexos

Entrevista Eduardo Lourenço $\quad 123$

$\begin{array}{ll}\text { Entrevista Silviano Santiago } & 128\end{array}$ 